\title{
A micro-Raman study of Cu-particulate-filled epoxy matrix composites
}

\author{
S. Tognana ${ }^{1 *}$, W. Salgueiro ${ }^{1}$, M. B. Valcarce ${ }^{2}$ \\ ${ }^{1}$ IFIMAT, Fac. de Cs. Exactas, CIFICEN CONICET- Universidad Nacional del Centro de la Provincia de Buenos Aires, \\ Pinto 399, (B7000GHG) Tandil, Argentina and Comisión de Investigaciones Científicas de la Provincia de Buenos Aires, \\ calle 526 entre 10 y 11 (1900) La Plata, Argentina. \\ ${ }^{2}$ División Electroquímica y Corrosión, INTEMA, CONICET, Universidad Nacional de Mar del Plata, Avenida Juan B. \\ Justo 4302, (7608 FDQ) Mar del Plata, Argentina
}

Received 4 October 2013; accepted in revised form 23 December 2013

\begin{abstract}
A micro-Raman study is carried out to investigate the influence of the filler on the curing process of bisphenol A diglycidyl ether (DGEBA)-based epoxy matrix composites. The composites are cured ( $14 \mathrm{~h}$ at $393 \mathrm{~K})$ with an anhydride (methyl tetrahydro phthalic anhydride, MTHPA, 100:90 pbw), catalyzed with a tertiary amine (0.7 pbw) and filled with a $30 \%$ volume of $\mathrm{Cu}$ particles of approximately $75 \mu \mathrm{m}$ in diameter. The experimental results are compared with those obtained for the same epoxy resin unfilled and for the same composite with $\mathrm{Cu}$ filler but not catalyzed. The micro-Raman experimental technique is used to search for information on the curing process in different regions of the matrix, near to and far from the copper filler, taking into account the results of differential-scanning-calorimetry measurements performed on the same composites. The results provide information on the influence of the copper filler on the curing process of the epoxy matrix. Differences were observed in the peaks associated with the epoxy ring and the ester group as a function of the distance to the nearest copper particle, but no differences were observed between the different composites.
\end{abstract}

Keywords: polymer composites, epoxy, micro-Raman spectroscopy

\section{Introduction}

Epoxy resins are used in structural applications ranging from high-performance composites for aerospace applications to encapsulants for the microelectronics industry because of their high thermal resistance, high tensile strength and modulus, and good chemical resistance. It is well known that the most important factors that influence their performance are the molecular architecture, the ratio between the epoxide and the hardener, and the cure conditions, frequently at a high temperature, which determine the final properties of the material. The influence of the filler particles on the curing is still a subject of study and clearly depends on the nature of the particles [1-5]. Epoxy matrix composites find new appli- cations every day in several areas of engineering and technology. For example, copper-filled composites have a high possibility of being used in microelectronics because the high thermal conductivity of copper allows the composite to be a good heat dissipator, which serves as protection to electronic devices $[6,7]$.

The matrix-particle interphases also play an important role. The physical properties of the polymeric composites can be significantly influenced by their thermal history; in fact, internal stresses are developed during the fabrication process and further thermal treatments. Microtechniques such as microcalorimetry [8], micro-Raman spectroscopy [9], and atomic-force microscopy have been used to study

\footnotetext{
${ }^{*}$ Corresponding author, e-mail: stognana@exa.unicen.edu.ar (C) BME-PT
} 
composites, and these techniques allow for deep analyses of the physics at work in the interphase and the matrix of such composites, opening a wide range of possibilities. The advantages of microtechniques are exploited in the present study.

Regarding the DGEBA-anhydride system catalyzed by a tertiary amine, this material has been studied by various authors, and the kinetic model that governs the curing reactions has been extensively discussed $[10,11]$. The curing has also been studied in a non-catalyzed system, in which it has been proposed that the reaction is initiated by impurities in a commercial tetrafunctional epoxy monomer [10]. We have recently observed that a non-catalyzed matrix filled with copper particles cures at a higher temperature than the related catalyzed system, and the results with differential scanning calorimetry is in preparation to be submitted. The present work is a continuation of a more general framework of study of epoxy-based composites containing different kinds of particles, in which some of the authors are involved. The main goals pursued are to investigate the effect produced by the inclusion of different kinds of particles, with a typical size of $100 \mu \mathrm{m}$, in an epoxy matrix and their influence on the thermal residual stresses [12-15]. The present work focuses on both types of composites (catalyzed and non-catalyzed) using micro-Raman spectroscopy. The aim of the work was to analyze the capability of this technique to garner information on the presence of inhomogeneities produced by the influence of filler (here, copper particles) on the curing of epoxy matrix composites. Information about the interphase between the copper and matrix in epoxy composites is sought in the framework of previous work of some of the authors, who study interphase phenomena in epoxy aluminum filled composites with different experimental techniques $[13,14,16]$.

\section{Experimental}

The samples studied were prepared using as matrix diglycidyl ether of bisphenol A (DGEBA) epoxy resin, cured with an anhydride (methyl tetrahydro phthalic anhydride MTHPA) (100:90 pbw), filled with $\mathrm{Cu}$ powder with a particle diameter of $\approx 75 \mu \mathrm{m}$ and with a filler volume fraction $\varphi=30 \%$. A catalyst (tertiary amine) was added ( $0.7 \mathrm{pbw})$ for the catalyzed sample. The catalyst was not used in the noncatalyzed sample. During the preparation of both samples, the mixture was stirred under vacuum until a good dispersion of the particles in the resin was attained. The compound was poured into a tubular Pyrex mold and placed in a horizontal position in a tubular oven. During the curing process, the mixture was heated to $393 \mathrm{~K}$ and maintained at a constant temperature for $14 \mathrm{~h}$. Following the same procedure, a sample of DGEBA-MTHPA-catalyser without copper particles (blank epoxy, cured at $393 \mathrm{~K}$ ) was prepared.

The Raman measurements were carried out using an Invia Reflex confocal Raman microprobe with an $\operatorname{Ar}^{+}$laser $(\lambda=514 \mathrm{~nm})$ and with a diode laser $(\lambda=786 \mathrm{~nm})$ in backscattering mode. An exposure time of $10 \mathrm{~s}$ and one accumulation were used with a $50 \times$ objective. The power of the laser was reduced using neutral density filters such that it did not exceed $1.05 \mathrm{~mW}$.

\section{Results and discussion}

\subsection{Raman spectroscopy, preliminary}

The blank epoxy was studied with a wavelength excitation source of $786 \mathrm{~nm}$; the results obtained (spectrum) are presented in Figure 1. It is important to emphasize that when studying the samples using a $514 \mathrm{~nm}$ excitation source, Raman results could not be obtained because only a saturation signal was observed.

A micro-Raman measurement was also performed in epoxy matrix composite filled with $\mathrm{Cu}$ particles ( $30 \%$ in volume), corresponding to the catalyzed system, using a $514 \mathrm{~nm}$ excitation source. A characteristic spectrum is also shown in Figure 1 for the purpose of comparing the results with those obtained when studying the blank epoxy. A third measurement with a $786 \mathrm{~nm}$ excitation source was carried out, but as can be seen in Figure 1, no Raman results were obtained. It is worth mentioning that a measurement of the non-catalyzed composite, using the $786 \mathrm{~nm}$ excitation source, yielded an analogous result to that of the catalyzed composite. We note that the measurements on the composites were performed in a region distant from the $\mathrm{Cu}$ particles to ensure that the result was obtained with the laser incident on the epoxy matrix.

From the analysis of both spectra shown in Figure 1, is possible to conclude that approximately the same peaks are present in the Raman spectra, although some differences are apparent for shift lower than $600 \mathrm{~cm}^{-1}$, where the peaks associated with the composite are smaller than the peaks associated with the 


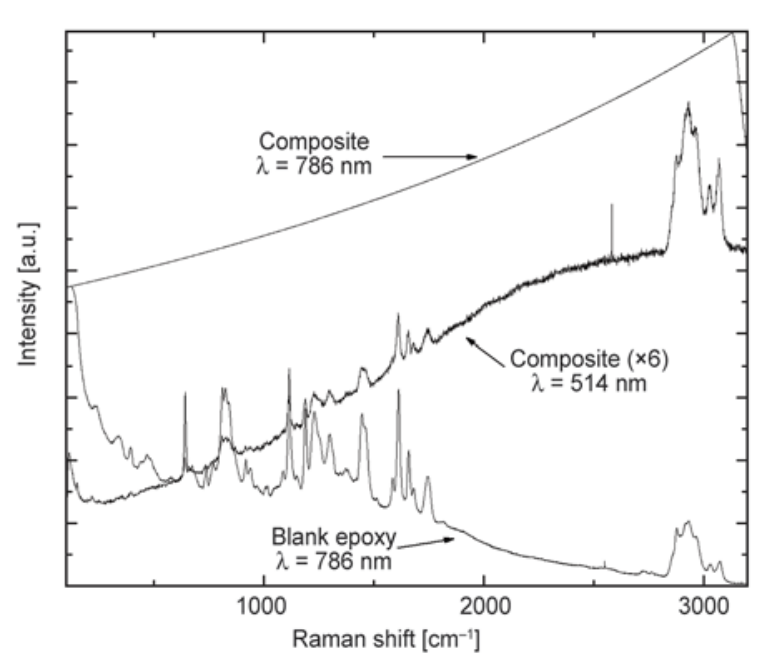

Figure 1. Raman spectra obtained from a blank epoxy sample and from a composite $(30 \% \mathrm{Cu})$. The laser wavelengths used for excitation are indicated for each spectrum. The laser power remained unchanged for the same wavelength.

epoxy. Furthermore, it is important to note that a direct comparison cannot be performed because different excitation wavelengths were used.

We remark that the difficulties in selecting the excitation wavelength for these materials arise because both matrix and filler can be detected at the same time. The differences observed in the Raman spectra using sources with different excitation wavelengths can be attributed to different effects. The saturation in the epoxy sample caused by the $514 \mathrm{~nm}$ excitation could be associated with the strong fluorescence observed when short wavelengths (visible range) are used [17].

The opposite situation is observed for the copperfilled composites; in this case, the $514 \mathrm{~nm}$ excitation source allows a good spectrum to be obtained, while no results are gained from the spectrum obtained with the $786 \mathrm{~nm}$ wavelength. An explanation for the latter effect could be provided by the surfaceenhanced Raman scattering (SERS) on $\mathrm{Cu}$, by which a significant increase in the scattering intensity is produced. The SERS effect in $\mathrm{Cu}$ is expected for wavelengths longer than $580 \mathrm{~nm}$ [18], and therefore, at the $514 \mathrm{~nm}$ wavelength, this effect is absent. On the other hand Resonant Raman scattering can occurs when the energy of the exciting light lies in the absorption band of the sample. The UV-visible reflectance spectra of the oxides grown on $\mathrm{Cu}$ show that the absorbance peaks at 237, 314 and $380 \mathrm{~nm}$ together with the shoulders at 462 and $550 \mathrm{~nm}$ are characteristics of $\mathrm{Cu}_{2} \mathrm{O}$ [19]. The $514 \mathrm{~nm}$ excitation source is nearer to some of the peaks mentioned and then the Resonant Raman scattering is present in $\mathrm{Cu}_{2} \mathrm{O}$. The intensity of the SERS effect is usually many times greater than the Resonant Raman [18]. This effect could be related to the good signal of epoxy obtained in the composites. This phenomenon must certainly be relevant when the Raman test is performed on or in the neighborhood of the $\mathrm{Cu}$ particles, but when the Raman measurement is performed on the epoxy matrix, the saturation is also observed, indicating that the incident radiation passes through of the matrix and ultimately reaches the copper surfaces.

The strong fluorescence and the difficulty that this fluorescence involves in the epoxies are well-known [20]; for example, using a laser source with same wavelength of our work, cycloaliphatic epoxy could not be studied; however, the hybrid systems of epoxy-methacrylate were free from fluorescence [21]. Then, the response of the epoxy systems to different wavelength excitation measurements is complex. Although there are signals of fluorescence in the composites that were studied using the $514 \mathrm{~nm}$ excitation source, the peaks can be easily analyzed. It is not clear yet if the fluorescence is lower in the composites and what the reason for this difference might be.

\subsection{Composite DGEBA + HY $918+30 \% \mathrm{Cu}$, non-catalyzed}

Micro-Raman spectroscopy was used to study composites filled with $30 \% \mathrm{Cu}$ particles (by volume) in the non-catalyzed epoxy matrix using an excitation wavelength of $514 \mathrm{~nm}$. The spectra were recorded at different positions along a straight line connecting two selected particles with a step size between measurements of $\approx 2 \mu \mathrm{m}$. In this mode the spatial resolution is $\approx 0.5 \mu \mathrm{m}$. A high confocality was used, allowing a best resolution at the expense of lower signal intensity. Depth resolution depends strongly on experimental setup being used besides of the optical properties of the sample. In this work, it was estimated that the scattered radiation originates from a volume with dimension of the order of $10 \mu \mathrm{m}$ in depth.

The recorded spectra are labeled $\left(E_{\mathrm{i}}, i=1,2, \ldots\right)$ according to the positions at which they were taken. In Figure 2, a micrograph is shown that indicates the line along which each spectrum was collected. The spectra obtained are presented in the same figure. 

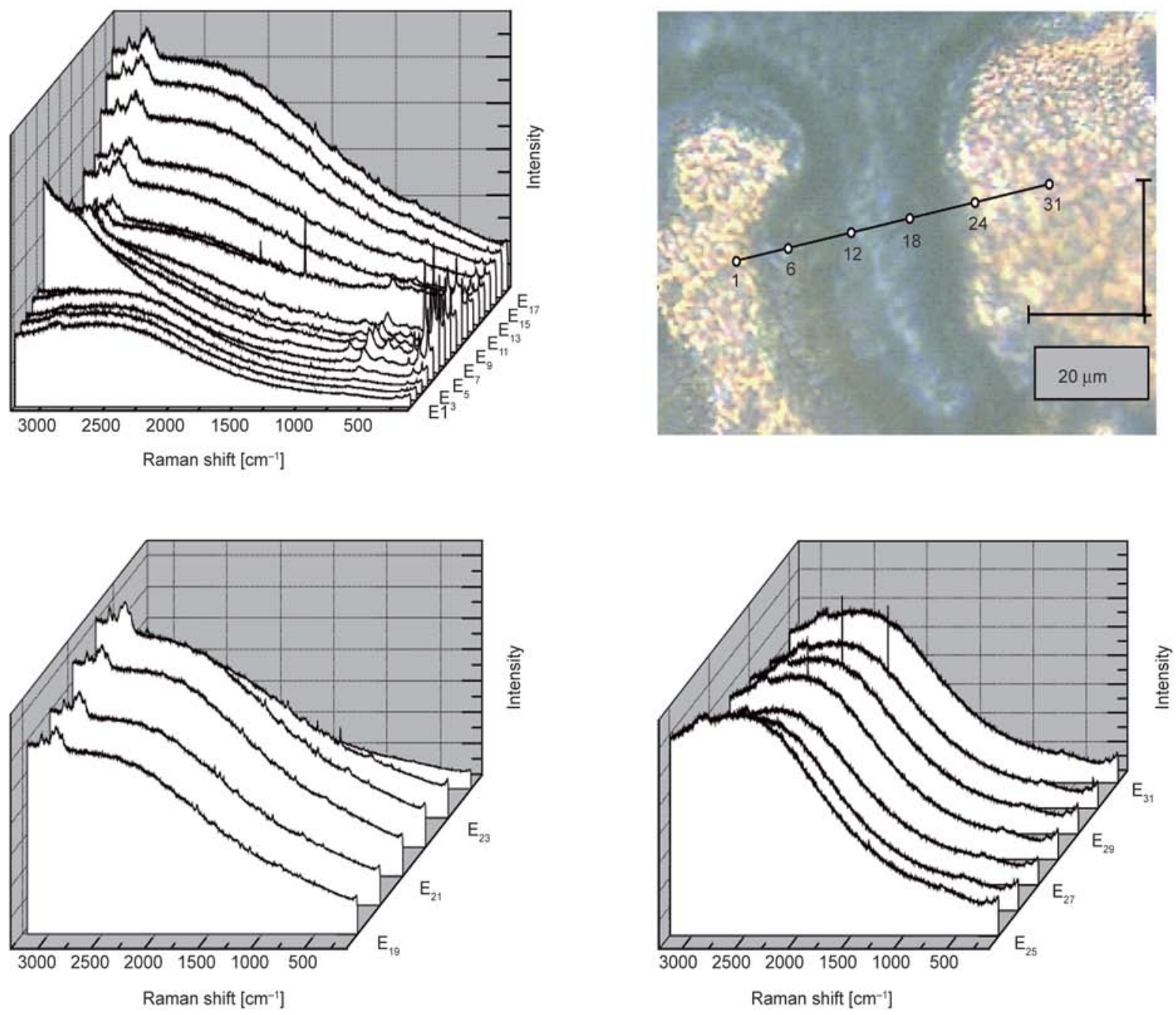

Figure 2. Micrograph and Raman spectra taken at different positions along a straight line connecting two selected copper particles in a DGEBA + HY $918+30 \% \mathrm{Cu}$ composite. The recorded spectra are labeled $\left(E_{\mathrm{i}}, i=1,2, \ldots\right)$ according to the positions shown on the micrograph.

In the spectra taken at positions $\mathrm{N}^{\circ} 1$ to $\mathrm{N}^{\circ} 5$, different peaks can be observed in the region at low Raman shifts $\left(<1000 \mathrm{~cm}^{-1}\right)$, which belong to the $\mathrm{Cu}$ oxides. The Raman technique is sensitive to the presence of $\mathrm{Cu}$ oxides, and, in particular, it has been reported in the literature that $\mathrm{Cu}_{2} \mathrm{O}$ exhibits peaks at 145, 220, 297, 411, 492, 633, and $786 \mathrm{~cm}^{-1}$ [18, 22]. In this work and, in particular, in the spectrum taken at position $\mathrm{N}^{\circ} 6$, peaks at $149,217,300,416$, $505 \mathrm{~cm}^{-1}$ with a shoulder at 530, 650 and $802 \mathrm{~cm}^{-1}$ can be observed. These peaks could be attributed to $\mathrm{Cu}_{2} \mathrm{O}$, although a peak of the matrix would be superposed on the peak at $650 \mathrm{~cm}^{-1}$. In addition, the identification of $\mathrm{CuO}$ with this technique is difficult to perform because the Raman scattering from $\mathrm{CuO}$ is much weaker than that from $\mathrm{Cu}_{2} \mathrm{O}$, and the main peak in the $\mathrm{CuO}$ spectrum lies too close to one of the most intense $\mathrm{Cu}_{2} \mathrm{O}$ peaks.
A fact that deserves attention is that the peaks at 300 and $802 \mathrm{~cm}^{-1}$ are not observed in the spectrum taken at position $\mathrm{N}^{\circ} 4$; furthermore, there is a peak at $530 \mathrm{~cm}^{-1}$ that, in the spectrum taken at position $\mathrm{N}^{\circ} 5$, becomes a peak at $505 \mathrm{~cm}^{-1}$ with a shoulder. An expanded detail view of the spectra is shown in Figure 3. The observed changes can be explained by taking into account that in the first spectrum, the Raman measurement is taken on the polished surface of the particle, but the spectrum taken at position $\mathrm{N}^{\circ} 5$ corresponds to a measurement taken with the laser incident on an unpolished surface covered with epoxy matrix.

The $\mathrm{Cu}$-oxide peaks are visible until the spectrum that was taken at position $\mathrm{N}^{\circ} 18$; therefore, the $\mathrm{Cu}$ oxide can be observed through the surface of the epoxy matrix. Between the spectra taken at positions $\mathrm{N}^{\circ} 19$ and $\mathrm{N}^{\circ} 24$, only the peaks corresponding 


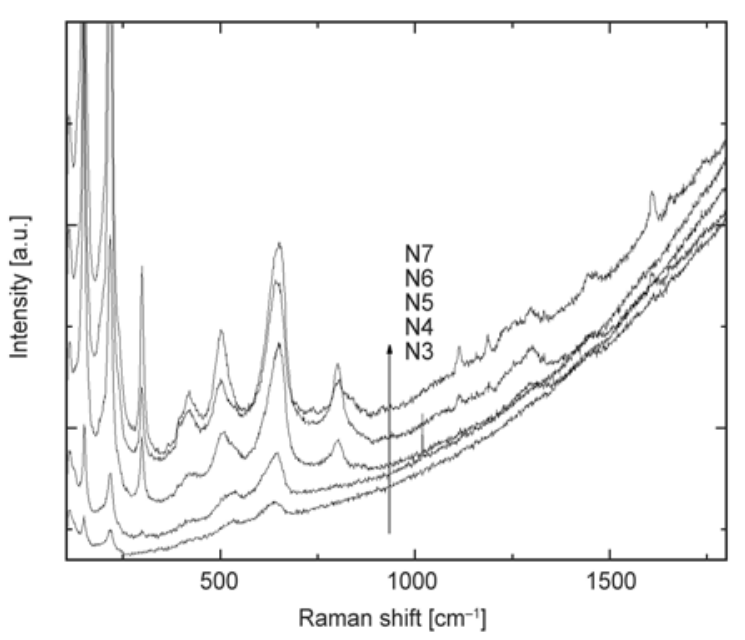

Figure 3. Raman spectra in the $100-1800 \mathrm{~cm}^{-1}$ Ramanshift region taken at positions near a copper particle

to the matrix are observed, but beginning with position $\mathrm{N}^{\circ} 25$, the measurements were once again taken with the laser incident on the surface of a copper particle, so the $\mathrm{Cu}_{2} \mathrm{O}$ peaks are observed again.

Therefore, we can conclude that in some cases, the Raman measurements allow the simultaneous observation of results that can be attributed to the matrix and to the particle surface, indicating that the scattered radiation is collected from a volume between the sample surface and the copper particle. This is also supported by the fact that the peaks corresponding to the epoxy increase in intensity when the distance to the nearest particle increases. It is worth mentioning that the radiation can not pass through the copper surface, then the volume of collection of radiation can be limited for this surface.

A schematic picture based on the above explanation is presented in the diagram of panel a in Figure 4. In
Figure $4 b$, the intensities of the peak that is characteristic of the epoxy at $1609 \mathrm{~cm}^{-1}$ (see below) for measurements taken at the different locations are also shown. As can be seen, the intensity increases when the distance to the nearest particle increases; this fact can be interpreted as a consequence of the greater epoxy volume where the scattering is produced.

The peaks corresponding to the epoxy matrix can be observed starting with the spectrum taken at position $\mathrm{N}^{\circ} 6$. The most important peaks were observed at 1113, 1186, 1230, 1253, 1300, 1332, $1457,1609,1655,1742 \mathrm{~cm}^{-1}$, a shoulder at 2875 , $2932,2967,3027$ and $3070 \mathrm{~cm}^{-1}$. The peaks located at Raman shifts higher than $2800 \mathrm{~cm}^{-1}$ could be associated with $\mathrm{C}-\mathrm{H}$ vibrations [10] or $\mathrm{CH}_{2}$ vibrations.

The peak at $1609 \mathrm{~cm}^{-1}$ is attributed to the aromatic ring (quadrant stretching) present in the epoxy monomer. In the literature, this peak has been reported at $1614 \mathrm{~cm}^{-1}[10,23-25]$. It is worth mentioning that there is a small shift of this peak compared with the results obtained from pure epoxy (see Figure 1), in which the peak is located at $1612 \mathrm{~cm}^{-1}$. This difference is also present in the Raman spectrum of the catalyzed composite (Figure 1), and it could be attributed to residual stress remaining from the curing process $[17,26]$. The peak at $1609 \mathrm{~cm}^{-1}$ can be clearly observed starting with the spectrum taken at position $\mathrm{N}^{\circ} 6$; therefore, from this position on, the epoxy monomer can be observed.

The peak at $1457 \mathrm{~cm}^{-1}$ can be attributed to the matrix, and to be specific, it can be interpreted as two superposed peaks located at 1445 and $1460 \mathrm{~cm}^{-1}$. Rocks et al. [10] attributed these peaks to the vibra-

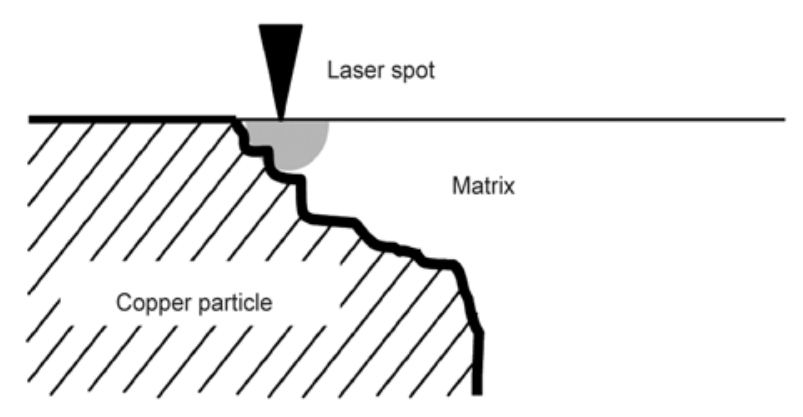

a)

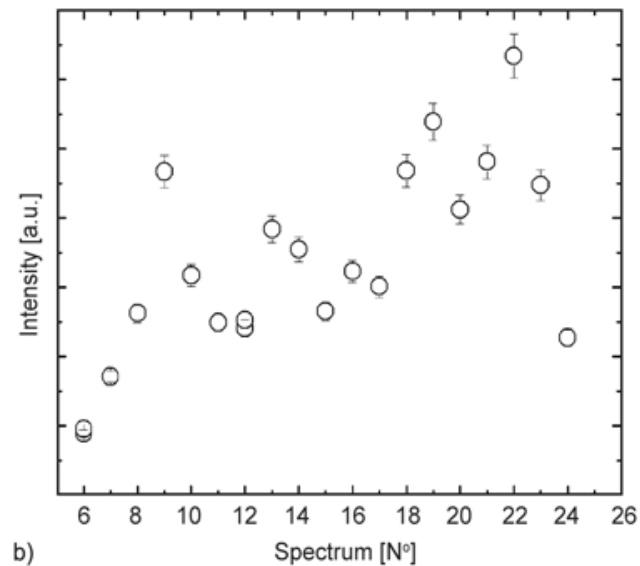

b)

Figure 4. Schematic diagram of the incidence of the laser on the sample (a), the intensity of the peak at $1609 \mathrm{~cm}^{-1}$ is shown for the different positions (b) 
tion $\delta \mathrm{CH}_{2}$ in the anhydride $\left(1449 \mathrm{~cm}^{-1}\right)$ and the vibration $\delta \mathrm{CH}_{2}+\delta_{\text {as }} \mathrm{CH}_{3}$ in the epoxy monomer $\left(1470 \mathrm{~cm}^{-1}\right)$. On the other hand, Kister et al. [27] identified a vibration $\delta_{\text {as }} \mathrm{CH}_{3}$ at $1452 \mathrm{~cm}^{-1}$, and Musto et al. [23] reported a peak at $1447 \mathrm{~cm}^{-1}$ belonging to the anhydride that is invariant during the curing.

The peak at $1300 \mathrm{~cm}^{-1}$ could be, according to Kister et al. [27], the superposition of three peaks located at 1313, 1302 and $1293 \mathrm{~cm}^{-1}$ and associated with the vibration $\delta_{2} \mathrm{CH}$. These last two peaks, 1300 and $1457 \mathrm{~cm}^{-1}$, are observed in the spectra obtained at positions $\mathrm{N}^{\circ} 5$ and $\mathrm{N}^{\circ} 6$, even though the peak at $1609 \mathrm{~cm}^{-1}$, which is characteristic of the aromatic ring of the epoxy matrix, is observed weakly or not at all. This could be evidence of the formation of some organic complex at the matrix-particle interface.

On the other hand, the peak at $1113 \mathrm{~cm}^{-1}$ is clearly evident in the spectrum taken at position $\mathrm{N}^{\circ} 6$ and could be attributed to the vibration of ether groups, $\mathrm{C}-\mathrm{O}-\mathrm{C}[9,28]$, while the peak at $1186 \mathrm{~cm}^{-1}$ can be associated to the in-plane deformation of the aromatic ring [23].

The peaks at 1230 and $1253 \mathrm{~cm}^{-1}$ diminish in intensity in a complex way as the curing progresses, and in particular, the peak at $1253 \mathrm{~cm}^{-1}$ can be attributed to the epoxy ring [23]. Following similar methods to those reported in the literature to study the curing process $[10,23]$, the ratio of intensity of the peak at $1253 \mathrm{~cm}^{-1}\left(I_{1253}\right)$ with respect to the peak at $1609 \mathrm{~cm}^{-1}\left(I_{1609}\right)$ was calculated for the different spectra, and the values obtained are shown in Figure 5. To estimate the intensity of each peak, the experimental data were fitted using Lorentzian functions, and the values of the area under the curve were used. The values obtained vary for the different positions, with higher values in the region near the particle, i.e., there are more epoxy rings or a worse-quality cure in this region. The variation in the values is primarily produced prior to the spectrum taken at position $\mathrm{N}^{\circ} 16$, after which the values obtained exhibit a higher dispersion. The results can be interpreted by considering that the variation is produced in the zone in which the $\mathrm{Cu}$-oxide peaks can also be observed in the Raman spectra. This gradual change could be explained by considering the Raman scattering as an average of the scattering at different depths, i.e., as the contribution of the scattering at the interface plus the scattering in the

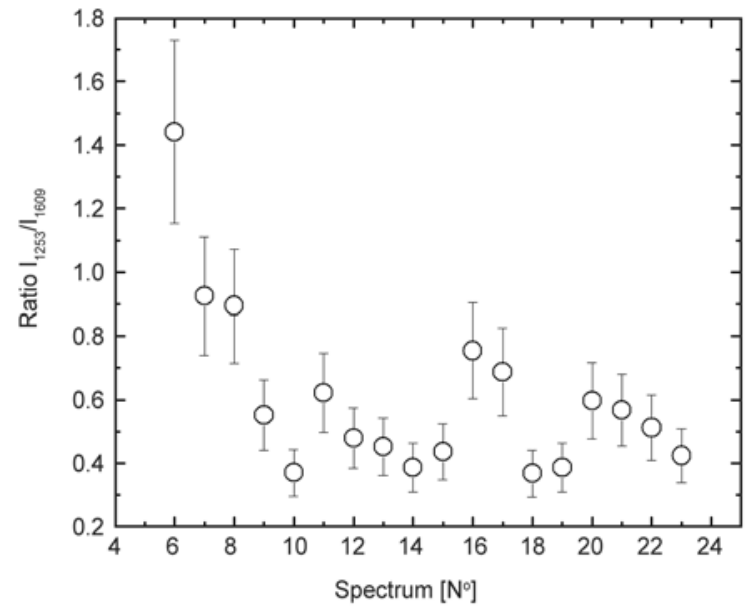

Figure 5. Ratio of the intensities of the peak at $1253 \mathrm{~cm}^{-1}$ with respect to the peak at $1609 \mathrm{~cm}^{-1}$ in the noncatalyzed composite. The spectra are labeled according to the positions at which they were recorded (see micrograph in Figure 2).

bulk. Therefore, a gradual variation can be expected as a result of the higher scattering in the bulk matrix. In particular, from the behavior of the intensity of the peak at $1253 \mathrm{~cm}^{-1}$, it could be concluded that a different number of open epoxy rings are present at the surface of the particle.

According to the literature $[10,23]$, the anhydride produces peaks at 1784 and $1854 \mathrm{~cm}^{-1}$ that can be assigned to $\mathrm{C}=\mathrm{O}$ groups; as the curing progresses, these peaks decrease in intensity. In this case, these peaks were not observed, so it can be concluded that the anhydride conversion is approximately complete.

The peak at $1742 \mathrm{~cm}^{-1}$ is a broad peak and could be associated with the peak reported at $1734 \mathrm{~cm}^{-1}$, which is characteristic of esterification involving the epoxy and anhydride groups $(\mathrm{C}=\mathrm{O}$ aliphatic ester), and an increase of this intensity has been observed during curing [23].

\subsection{Composite \\ DGEBA + HY 918 + catalyst + 30\% Cu}

The DGEBA-anhydride system cured in the presence of a catalyst and containing a $30 \%$ volume fraction of $\mathrm{Cu}$ particles was studied using a $514 \mathrm{~nm}$ wavelength excitation source in a micro-Raman measurement along a straight line connecting two copper particles. Similar to the presentation of the results in the previous subsection, the spectra are labeled according to the locations at which they were collected in the composite. In Figure 6, the Raman spectra are shown, and the region between 

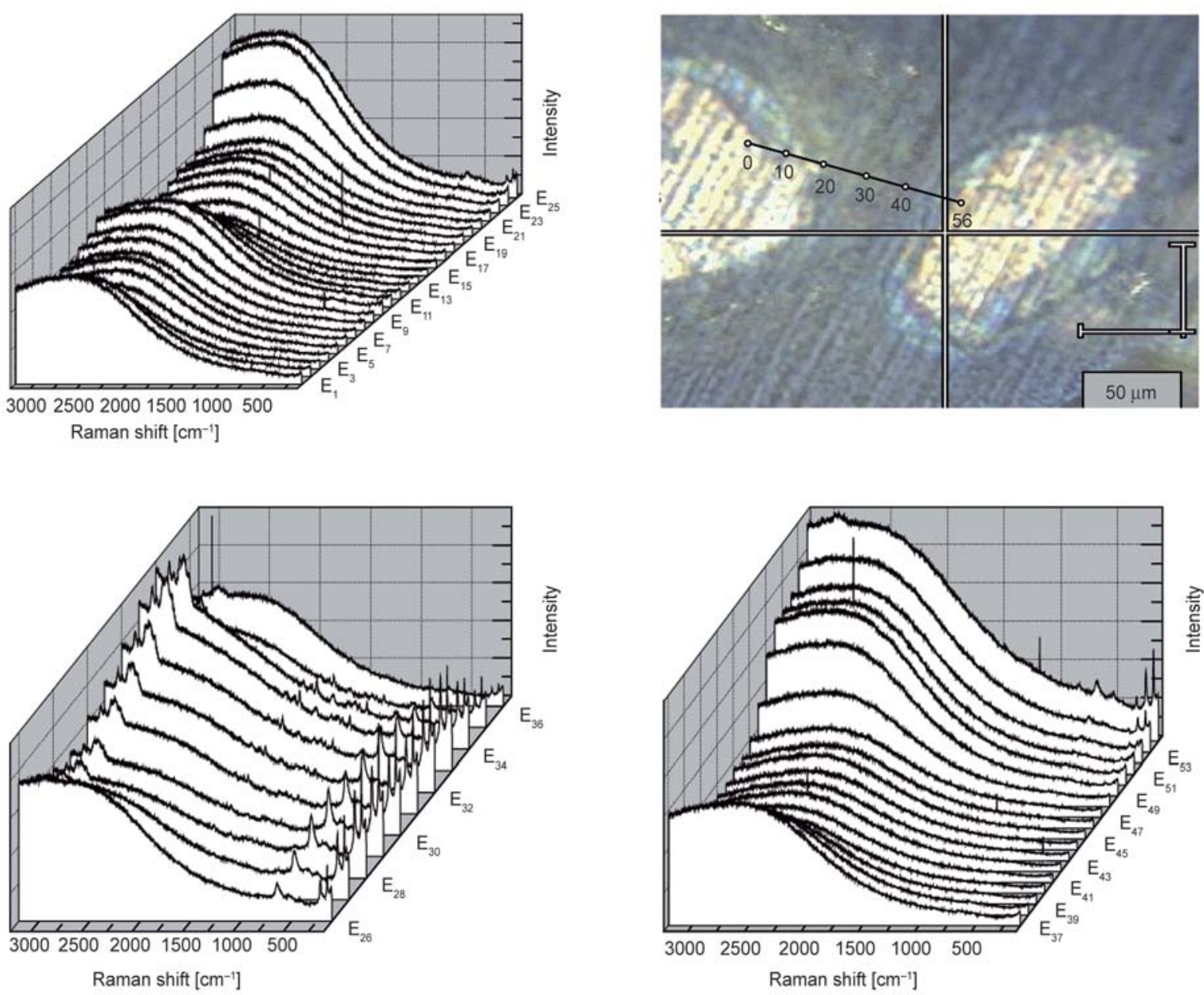

Figure 6. Micrograph and Raman spectra taken at different positions between two copper particles in the DGEBA + HY918 + catalyst $+30 \% \mathrm{Cu}$ composite

the copper particles wherein they were collected is indicated in the micrograph.

As can be seen in Figure 6, various characteristic regions can be identified: First, from the spectrum taken at position $\mathrm{N}^{\circ} 1$ to the spectrum taken at position $\mathrm{N}^{\mathrm{o}} 25$, only a small trace of the peaks corresponding to the $\mathrm{Cu}$ oxide can be observed, primarily in the spectra that were taken far from the particles. In the spectra taken from position $\mathrm{N}^{\circ} 26$ to position $\mathrm{N}^{\circ} 36$, the peaks associated with the $\mathrm{Cu}$ oxide are clearly visible, and the peaks corresponding to the epoxy matrix increase in intensity, indicating that both materials, the $\mathrm{Cu}$ oxide and the matrix, are clearly present in the Raman scattering. Therefore, the epoxy and the interface between the particle and the matrix contribute to the Raman scattering.

From the spectrum taken at position $\mathrm{N}^{\circ} 37$ onward, it is clear that the $\mathrm{Cu}$-oxide peaks are barely observed, and it is clear that the epoxy peaks are absent, although in the spectrum taken at position $\mathrm{N}^{\circ} 48$ and subsequent spectra, the $\mathrm{Cu}$-oxide peaks increase in intensity.

The peaks observed in the Raman spectra are the same that are observed in the non-catalyzed composites, so a further explanation of them will not be given. However, certain peaks will be analyzed. In the intermediate region of the Raman measurement line (in the spectra taken from position $\mathrm{N}^{\circ} 28$ to position $\mathrm{N}^{\circ} 36$ ), where the major changes in the peaks corresponding to the matrix are observed, the ratio of the intensity of the peak positioned at $1253 \mathrm{~cm}^{-1}$ (epoxy ring) with respect to the intensity of the peak at $1609 \mathrm{~cm}^{-1}$ was calculated. In addition, the broad peak at $1740 \mathrm{~cm}^{-1}$ was fitted using two Lorentzian functions, one centered at $1735 \mathrm{~cm}^{-1}$ and the other centered at $1747 \mathrm{~cm}^{-1}$. The curve at $1735 \mathrm{~cm}^{-1}$ can be associated to ester formation involving the epoxy and anhydride groups, and the ratio of the intensity of this peak with respect to the intensity of the peak at $1609 \mathrm{~cm}^{-1}$ was calculated. The values of both intensity ratios, corresponding to the peak at 
$1253 \mathrm{~cm}^{-1}$ and the peak at $173 \mathrm{~cm}^{-1}$, are shown in Figure 7. In the inset of the same figure, the fit to the experimental data using two Lorentzian functions is shown. The results obtained for the two investigated peaks demonstrate opposite tendencies and indicate that there are variations in the curing quality of the sample as a function of the measurement location with respect to the nearest copper particle. This fact was interpreted as arising from a higher number of epoxy rings near to the copper particle, meaning a lower esterification.

In both cases, the results indicate that there is a variation in the number of open epoxy rings depending on the distance to the particle, although a definitive conclusion regarding the general behavior could not be obtained from the data. However, a change in the cure kinetics due to the presence of copper is not discarded, and more information is necessary. In this study, the kinetics has not been considered because the aim is focused on finding differences between different regions of the composites. The use of micro-Raman spectroscopy to study the kinetics in the different regions of the composites increases the experimental complexity.

No significant variations are observed in the Raman spectra when a comparison is made between the spectra obtained from the catalyzed and non-catalyzed samples; therefore, it is possible to assume a similar chemical structure of the molecular chains

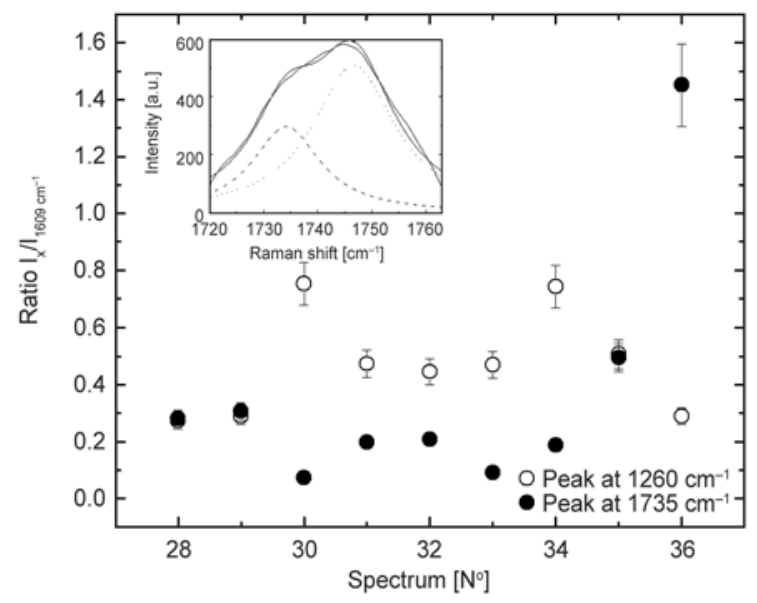

Figure 7. Ratios of the intensities of the peak at $1253 \mathrm{~cm}^{-1}$ and the peak at $1735 \mathrm{~cm}^{-1}$ with respect to the peak at $1609 \mathrm{~cm}^{-1}$ in the catalyzed composite. The spectra are labeled according to the positions at which they were recorded. In the inset, the fit of the peak at approximately $1740 \mathrm{~cm}^{-1}$ with two Lorentzian functions is shown. in both samples. On this topic, Rocks et al. [10] proposed models for the possible types of curing reactions depending on whether there is a catalyst present. When there is a catalyst present, the catalyst reacts with the epoxy monomer, forming a zwitterion that contains an ammonium cation and a carboxylate anion. This carboxylate may be considered as an active center for alternating chainwise copolymerization. In the case of the non-catalyzed reaction, hydroxyl groups, which are present in the epoxy monomer, attack the anhydride, forming a monoester with a free carboxyl group. The free carboxyl group then reacts with an epoxy ring to yield a diester and a new hydroxyl group, allowing the curing process to continue. For more details about the chemistry that is involved, see for example the equations that are presented in the studies [10,23]. Therefore, although the curing reaction is different for the two samples, the Raman results do not permit the identification of unambiguous differences between them [10]. Preliminary results, which were obtained using DSC in epoxy-copper composites with and without a catalyst, have shown changes in the curing exothermic peaks; thus, a change in the curing kinetics can be expected. This finding may also provide evidence that the copper is interacting chemically with the epoxy during the curing and that this interaction is not limited to be only a 'physical' interaction due to the high thermal conductivity of the copper. It is worthwhile mentioning that the time for curing is 14 hours, which is sufficient to reach thermal equilibrium. Studies that use other types of filler are also underway; for example, the use of quartz [15] or aluminum [13, 14, 16] particles has shown to not have an influence on the curing as important as the copper particles, although these materials have a thermal conductivity lower than that of copper. A study that uses particles with a thermal conductivity similar to that of copper could address the problem of discerning the difference between the physical and chemical interaction of copper with the epoxy.

On the other hand, secondary reactions during the curing process of epoxy forming ether groups can be produced [10, 23]. In this work, although some peaks that can be attributed to ether groups can be observed, evidence of a high degree of etherification with respect to esterification was not observed in the composites that were studied. 


\section{Conclusions}

In this work, epoxy-based particulate composites, both catalyzed with a tertiary amine and non-catalyzed, were studied using micro-Raman spectroscopy. The spectra were recorded in different regions of the sample: the $\mathrm{Cu}$ particles and the epoxy matrix.

Because of the characteristics of the samples, two different excitation sources were used, and it was found that it is possible to study the copper-filled composites using an excitation with a wavelength of $514 \mathrm{~nm}$, while when an excitation with wavelength of $786 \mathrm{~nm}$ is used, saturation is observed. These results are interpreted as an effect of the $\mathrm{Cu}$ particles.

The peaks observed in the spectra were characterized according to their sources. The peaks corresponding to the $\mathrm{Cu}$ oxide are observed even when the measurements are performed on the matrix; this indicates that the particle surface can be seen below the matrix, due to the penetration of the laser radiation into the matrix.

The peak associated with the epoxy ring was analyzed by evaluating the ratio of its intensity with respect to the intensity of the peak at $1609 \mathrm{~cm}^{-1}$ that is associated with the aromatic ring. These ratios were analyzed in both the catalyzed and non-catalyzed composites, and their behavior, as a function of the distance to the nearest copper particle, is interpreted as a variation of the epoxy-ring signal when the distance to the nearest particle increases. The results are attributed to a smaller number of open epoxy rings near the particles. A similar evaluation for the peak associated with the ester-group formation was also performed in the non-catalyzed sample, and the opposite behavior with respect to that corresponding to the epoxy ring was observed.

No differences were observed between the different curing reactions in the presence or absence of the catalyst.

\section{Acnowledgements}

The authors acknowledge to Comisión de Investigaciones Científicas de la Provincia de Buenos Aires, SECAT- Universidad Nacional del Centro de la Provincia de Buenos Aires (Argentina), Universidad Nacional de Mar del Plata and the National Research Council (CONICET).

\section{References}

[1] Omrani A., Simon L. C., Rostami A. A.: The effects of alumina nanoparticle on the properties of an epoxy resin system. Materials Chemistry and Physics, 114, 145-150 (2009).

DOI: $10.1016 / \mathrm{j}$. matchemphys.2008.08.090

[2] Hong S. G., Wang T. C.: The effect of copper oxides on the curing of brominated epoxy resins. Thermochimica Acta, 237, 305-316 (1994). DOI: 10.1016/0040-6031(94)80188-6

[3] Fu Y., Zhong W-H.: Cure kinetics behavior of a functionalized graphitic nanofiber modified epoxy resin. Thermochimica Acta, 516, 58-63 (2011). DOI: $10.1016 /$ j.tca.2011.01.016

[4] Tarrío-Saavedra J., López-Beceiro J., Naya S., Gracia C., Artiaga R.: Controversial effects of fumed silica on the curing and thermomechanical properties of epoxy composites. Express Polymer Letters, 4, 382-395 (2010). DOI: 10.3144 /expresspolymlett.2010.48

[5] Harsch M., Karger-Kocsis J., Holst M.: Influence of fillers and additives on the cure kinetics of an epoxy/ anhydride resin. European Polymer Journal, 43, 11681178 (2007). DOI: 10.1016/j.eurpolymj.2007.01.025

[6] Mamunya Y. P., Davydenko V. V., Pissis P., Lebedev E. V.: Electrical and thermal conductivity of polymers filled with metal powders. European Polymer Journal, 38, 1887-1897 (2002). DOI: 10.1016/S0014-3057(02)00064-2

[7] Boudenne A., Ibos L., Fois M., Majesté J. C., Géhin E.: Electrical and thermal behavior of polypropylene filled with copper particles. Composites Part A: Applied Science and Manufacturing, 36, 1545-1554 (2005). DOI: 10.1016/j.compositesa.2005.02.005

[8] Van Assche G., Van Mele B.: Interphase formation in model composites studied by micro-thermal analysis. Polymer, 43, 4605-4610 (2002).

DOI: $10.1016 / \mathrm{S} 0032-3861(02) 00298-7$

[9] Spencer P., Wang Y., Walker M. P., Wieliczka D. M., Swafford J. R.: Interfacial chemistry of the dentin/ adhesive bond. Journal of Dental Research, 79, 14581463 (2000). DOI: $10.1177 / 00220345000790070501$

[10] Rocks J., Rintoul L., Vohwinkel F., George G.: The kinetics and mechanism of cure of an amino-glycidyl epoxy resin by a co-anhydride as studied by FT-Raman spectroscopy. Polymer, 45, 6799-6811 (2004). DOI: 10.1016/J.POLYMER.2004.07.066

[11] Mauri A. N., Riccardi C. C.: The effect of epoxy excess on the kinetics of an epoxy-anhydride system. Journal of Applied Polymer Science, 85, 2342-2349 (2002).

DOI: $10.1002 /$ app.10867 
[12] Tognana S., Salgueiro W., Somoza A., Pomarico J. A., Ranea Sandoval H. F.: Influence of the filler content on the thermal expansion behavior of an epoxy matrix particulate composite. Materials Science and Engineering: B, 157, 26-31 (2009).

DOI: $10.1016 /$ j.mseb.2008.12.003

[13] Goyanes S., Rubiolo G., Salgueiro W., Somoza A.: On the free volume evolution in a deformed epoxy composite. A positron annihilation study. Polymer, 46, 9081-9087 (2005).

DOI: $10.1016 /$ j.polymer.2005.07.020

[14] Goyanes S., Rubiolo G., Marzocca A., Salgueiro W., Somoza A., Consolati G., Mondragon I.: Yield and internal stresses in aluminum filled epoxy resin. A compression test and positron annihilation analysis. Polymer, 44, 3193-3199 (2003). DOI: $10.1016 / \mathrm{S} 0032-3861(03) 00229-5$

[15] Marzocca A. J., Somoza A., Goyanes S. N., Salgueiro W., König P.: Characterization of free volume in particulate-filled epoxy resin by means of dynamic mechanical analysis and positron annihilation lifetime spectroscopy. Polymer International, 51, 1277-1284 (2002). DOI: $10.1002 /$ pi.1017

[16] Tognana S., Salgueiro W., Somoza A.: On the matrixparticle interphase in epoxy-based composites. Journal of Alloys and Compounds, 495, 588-591 (2010).

DOI: $10.1016 /$ j.jallcom.2009.10.058

[17] Colomban Ph., Gouadec G., Mathez J., Tschiember J., Pérès P.: Raman stress measurement in opaque industrial $\mathrm{C}_{\mathrm{f}} /$ epoxy composites submitted to tensile strain. Composites Part A: Applied Science and Manufacturing, 37, 646-651 (2006).

DOI: 10.1016/j.compositesa.2005.05.004

[18] Hamilton J. C., Farmer J. C., Anderson R. J.: In situ raman spectroscopy of anodic films formed on copper and silver in sodium hydroxide solution. Journal of the Electrochemical Society, 133, 739-745 (1986). DOI: $10.1149 / 1.2108666$

[19] Valcarce M. B., Vázquez M.: Phosphate ions used as green inhibitor against copper corrosion in tap water. Corrosion Science, 52, 1413-1420 (2010).

DOI: $10.1016 /$ j.corsci.2009.12.015

[20] Xue G.: Fourier transform raman spectroscopy and its application for the analysis of polymeric materials. Progress in Polymer Science, 22, 313-406 (1997). DOI: 10.1016/S0079-6700(96)00006-8
[21] Asmussen S., Schroeder W., dell'Erba I., Vallo C.: Monitoring of visible light photopolymerization of an epoxy/dimethacrylate hybrid system by Raman and near-infrared spectroscopies. Polymer Testing, 32, 1283-1289 (2013).

DOI: $10.1016 /$ j.polymertesting.2013.08.005

[22] Niaura G.: Surface-enhanced Raman spectroscopic observation of two kinds of adsorbed $\mathrm{OH}^{-}$ions at copper electrode. Electrochimica Acta, 45, 3507-3519 (2000). DOI: $10.1016 / \mathrm{S} 0013-4686(00) 00434-5$

[23] Musto P., Abbate M., Ragosta G., Scarinzi G.: A study by Raman, near-infrared and dynamic-mechanical spectroscopies on the curing behaviour, molecular structure and viscoelastic properties of epoxy/anhydride networks. Polymer, 48, 3703-3716 (2007). DOI: $10.1016 /$ j.polymer.2007.04.042

[24] deBakker C. J., George G. A., St John N. A., Fredericks P. M.: The kinetics of the cure of an advanced epoxy resin by Fourier transform Raman and near-IR spectroscopy. Spectrochimica Acta Part A: Molecular Spectroscopy, 49, 739-752 (1993). DOI: $10.1016 / 0584-8539(93) 80098-\mathrm{U}$

[25] Merad L., Cochez M., Margueron S., Jauchem F., Ferriol M., Benyoucef B., Bourson P.: In-situ monitoring of the curing of epoxy resins by Raman spectroscopy. Polymer Testing, 28, 42-45 (2009). DOI: $10.1016 / j . p o l y m e r t e s t i n g .2008 .10 .006$

[26] Bennett J. A., Young R. J.: Micromechanical aspects of fibre/crack interactions in an aramid/epoxy composite. Composites Science and Technology, 57, 945-956 (1997). DOI: $10.1016 / \mathrm{S} 0266-3538(97) 00023-7$

[27] Kister G., Cassanas G., Vert M.: Effects of morphology, conformation and configuration on the IR and Raman spectra of various poly(lactic acid)s. Polymer, 39, 267-273 (1998).

DOI: $10.1016 / \mathrm{S} 0032-3861(97) 00229-2$

[28] Wang Y., Spencer P.: Hybridization efficiency of the adhesive/dentin interface with wet bonding. Journal of Dental Research, 82, 141-145 (2003). DOI: $10.1177 / 154405910308200213$ 